\title{
Rancang Bangun Sistem Visi Terkendali Untuk ROV
}

\author{
Fahri D. Marajabesi' ${ }^{1}$, Iis Hamsir Ayub Wahab², Achmad P. Sardju ${ }^{3}$ \\ ${ }^{1}$ Fakultas Teknik Elektro \\ UniversitasKhairun \\ Ternate, Indonesia \\ email: fahridenimarajabesi@gmail.com, hamsir@ unkhair.ac.id, mattsardju@gmail .com
}

\begin{abstract}
ABSTRAK-ROV (Remotely operated vehicle) merupakan perangkat yang mampu melakukan pergerakan dan eksplorasi dibawah laut yang dikendalikan dengan sistem pengkontrol. Namun, penelitian wahana bawah air (dalam laut) sampai saat ini masih kurang berkembang di Maluku Utara khususnya di Ternate. Sistem visi ROV terkendali adalah pandangan ROV dengan menggunakan kamera sebagai perangkat untuk pengambilan gambar atau video ekplorasi objek bawah laut, seperti pemetaan, survei, pemotretan bawah air, riset, dan misi penyelamatan, yang akan digunakan oleh SAR dan di kendalikann menggukan joystick. Oleh karena itu diharapkan sebuah ROV dapat membantu dalam monitoring dan eksplorasi bawah air. Pada penelitian ini akan membahas bagaimana cara mengendalikan sistem visi ROV di dalam laut. Kamera pada ROV sangat berguna untuk membantu operator dalam mengendalikan sebuah ROV ketika ROV tersebut sudah tidak tampak dari atas permukaan air serta membantu operator dalam mengamati kondisi atau keadaan bawah air dengan kedalaman tertentu, dari permukaan air laut dan mikrokontroler yang akan menerima dan memproses data yang akan menampilkan gambar maupun video di layar komputer.

Tujuan penelitian ini adalah dimana untuk merancang sistem visi ROV Terkendali dengan kamera webcam dan kontrol menggunakan joystick sebagai suatu kesatuan dari robot bawah air sendiri yang nantinya dapat digunakan untuk mengetahui kondisi atau keadaan bawah air dengan kedalaman tertentu.
\end{abstract}

Kata kunci : Sistem Visi Rov Terkendali, Kamera Webcam, Arduino Uno, Motor Servo, Joystick.

\section{Pendahuluan}

Indonesia yang terkenal dengan sebutan negara kepulauan atau negara maritim memiliki laut yang lebih luas dari pada daratan. Luas lautan Indonesia 3,1 juta $\mathrm{km}^{2}$ atau $62 \%$ dari luas seluruh wilayah. Dengan melihat karakteristik wilayah yang merupakan perairan, maka dapat dikatakan bahwa, pengembangan potensi unggulan disektor kelautan mempunyai prospek yang sangat menjanjikan. Untuk dapat memanfaatkan potensi sumber daya yang terdapat di lautan tersebut, maka perlu dilakukan penelitian lebih jauh dengan memanfaatkan teknologi yang ada untuk mendapatkan informasi mengenai sumber daya kelautan dan perikanan di wilayah Indonesia.

Terdapat 2 (dua) macam wahana bawah air, yaitu Remotely Operated Vehicles (ROVs) and Autonomous Underwater Vehicles (AUVs) [1]-[3]. Kedua jenis wahana ini biasa disebut juga robot bawah air yang merupakan bagian integral dari peralatan ilmiah untuk menjelajahi lautan dan samudera [2]. Sistem monitoring dan gripper pada ROV (Remotely operated vehicle) untuk pengamatan dan eksplorasi bawah laut. Sistem ini dilengkapi perangkat monitoring yaitu kamera dan sensor suhu DS18B20, sedangkan perangkat untuk eksplorasi dilengkapi dengan gripper yang digerakkan oleh pengkontrol. Kamera dan sensor suhu DS18B20 diproses oleh Raspberry Pi dan dihubungkan ke-laptop mengunakan kabel LAN, kemudian hasil dari kamera akan ditampilkan dilayar laptop. Bisa juga dihubungkan menggunakan kabel umbilical ke ruangan kontrol dan operator di atas permukaan air (kapal, rig atau barge). Melalui kabel umbilical, tenaga listrik dan juga perintah-perintah, atau sinyal-sinyal kontrol, disampaikan dari perangkat kontrol ke ROV, secara dua arah. Kemampuannya bisa di lengkapi dengan menambahkan peralatan atau sensor tertentu seperti sonar, magnetometer, kamera foto, manipulator atau lengan robotik, pengambil sampel air, dan alat pengukur kejernihan air, penetrasi cahaya, serta temperatur, transponder, kompas, odometer, bathy (data kedalaman) dan lain-lain tergantung dari keperluan dan tujuan surveinya [4].

\section{SENSOR KAMERA}

Kamera adalah alat untuk manangkap gelombang cahaya yang dipantulkan oleh objek, sehingga objek tersebut dapat dipetakan dalam bentuk citra. Pada kamera digital citra yang dihasilkan merupakan citra dalam bentuk digital. Secara umum kamera digital terdiri dari lensa, sensor cahaya, dan digitizer. Lensa pada kamera berguna memfokuskan cahaya yang di terima sehingga tepat mengenai sensor cahaya. Sensor cahaya (phototransistor/photodiode) yang disusun dalam bentuk matrik. Sinyal analog yang di hasilkan oleh sensor lalu di konversikan ke dalam bentuk digital oleh digitizer sehingga sinyal digital inilah yang dihasilkan oleh kamera digital. Dan kamera yang digunakan adalah Webcam Logitech 


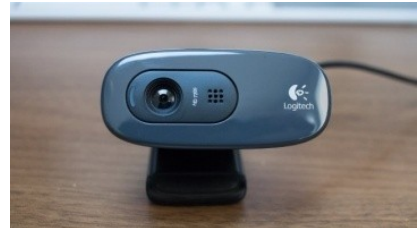

Gambar 1. Webcam Logitech

Webcam merupakan gabungan dari kata web dan camera. Webcam sendiri sebutan bagi kamera real-time (bermakna keadaan pada saat ini juga) yang gambarnya bisa diakses atau dilihat melalui internet, program instant messaging seperti Yahoo Messenger, AOL Instant Messenger (AIM), Windows Live Messenger , dan Skype, dan lainnya. Istilah "webcam" sendiri mengarah pada jenis kamera yang digunakan untuk kebutuhan layanan berbasis web. Webcam sendiri biasanya digunakan untuk keperluan konferensi jarak jauh atau juga sebagai kamera pemantau.

WebCam adalah sebuah periferal berupa kamera sebagai pengambil citra/gambar dan mikropon ( optional ) sebagai pengambil suara/audio yang dikendalikan oleh sebuah komputer atau oleh jaringan komputer. Gambar yang diambil oleh WebCam ditampilkan ke layar monitor, karena dikendalikan oleh komputer maka ada interface atau port yang digunakan untuk menghubungkan WebCam dengan komputer atau jaringan. Ada beberapa orang mengartikan WebCam sebagai Web pages + Camera, karena dengan menggunakan WebCam untuk mengambil gambar video secara aktual bisa langsung di upload bila komputer yang mengendalikan terkoneksi internet.

\section{ARduino Uno R3}

Arduino adalah mikrokontroler singleboard yang dirancang untuk mempermudah penggunanya karena sifatnya yang open source. Piranti ini dapat dimanfaatkan untuk membuat rangkaian elektronik dari yang sederhana hingga yang kompleks. Arduino Uno dilengkapai dengan osilator $16 \mathrm{MHz}$, regulator 5 volt. Pada Arduino Uno terdapat sejumlah pin yaitu 0-13 yang merupakan input dan pin A0-A5 yang merupakan input analog. Arduino Uno dilengkapai dengan konektor USB, konektor catu daya, header ICSP, dan tombol reset, SRAM berukuran $2 \mathrm{~KB}$, flash memory berukuran $32 \mathrm{~KB}$ dan EPROM untuk menyimpan data.

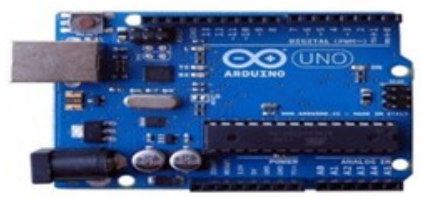

Gambar 2. Arduino UNO R3

Gambar diatas merupakan salah satu gambar dari versi arduino, yaitu Arduino Uno R3. Arduino Uno R3 adalah board berbasis mikrokontroler ATmega328. Memiliki 14 pin digital input/outpuy dan 6 pin input analog, $16 \mathrm{MHz}$ osilator kristal, koneksi USB, power jack, ICSP header dan tombol reset. Semua ini yang diperlukan untuk mendukung mikrokontroler.

\section{Metode Penelitian}

Pada tugas akhir ini bagaimana membuat sebuah sistem visi ROV terkendali agar dapat di kendalikan dari jarak jauh, sistem visi ROV ini yang dilengkapi dengan dua buah motor penggerak (thruster), driver motor servo, mikrokontroler Arduino Uno R3, pengendali arah (joystick control), kamera pemantau, lampu atau sistem pencahayaan (lighting), legulator 5 volt dan 12 volt. Perancangan sistem visi ROV terkendali ini terdiri dari 4 bagian utama, yaitu input yang terdiri dari kamera sebagai perangkat untuk mengambil gambar/video dibawah laut, joystick sebagai pengendali arah kamera pada motor servo, dan Bagian proses yang terdiri dari Arduino Uno R3 yang berfungsi untuk mengolah data hasil dari bagian input, dan bagian output yang terdiri dari laptop untuk menampilkan hasil dari kamera. Adapun diagram blok kendali Sistem visi ROV terkendali ditunjukan pada gambar 3 .

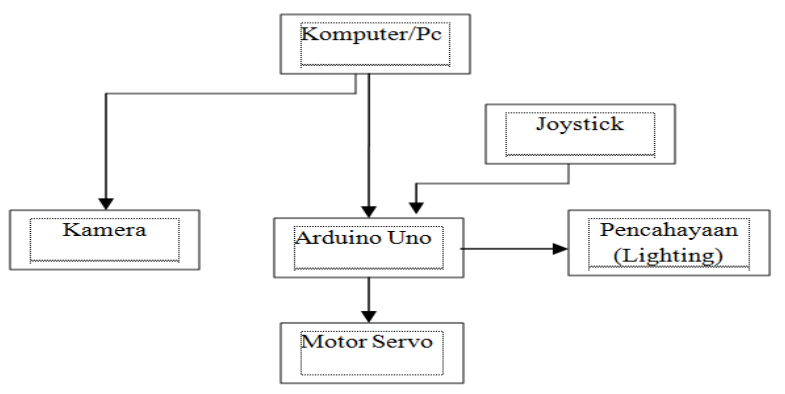

Gambar 3. Diagram blok kendali

\section{Perancangan Hardware}

Perancangan hardware yang pertama adalah perancangan pengendali sistem visi Rov, Dengan menggunakan joystick agar dapat mengendalikan motor servo yang terhubung dengan kamera pemantau dan sistem pencahayaan pada ROV tersebut. Yang kedua adalah merancang sebuah konektor RJ45 dengan menggunkan kabel LAN, yang dihubungkan dengan kamera, laptop Arduino Uno, Joystick dan sistem pencahyaan. Dan yang terakhir adalah perancangan power suply dc 5 volt dan 12 volt untuk mengaktifkan, arduino, joystick, motor servo, lighting, dan kamera yang akan mengambil gambar atau video pada saat pengujian sistem tersebut.

\section{Perancangan software}

Perancangan sofware dilakakukan untuk mempermudah dalam pembuatan program pada mikrokontroler Arduino. Dengan merancang algoritma jalanya program, maka dengan mudah akan dapat memprogram mikontroller sebagai pemroses sensor kamera menjadi tampilan dalam monitor. 


\section{Flowchart Penelitian}

Penelitian ini akan dilaksanakan seperti Flowchart di bawah ini:

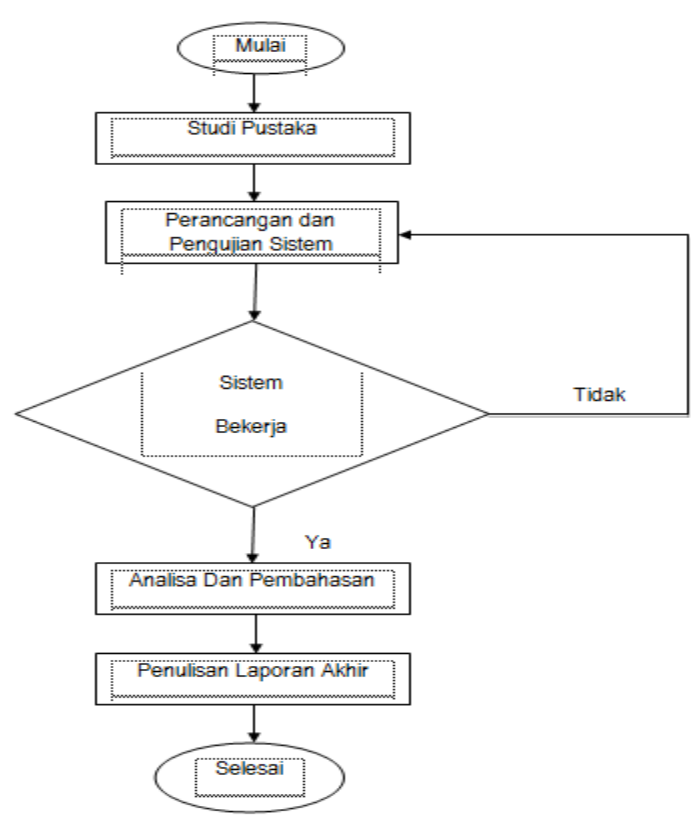

Gambar 4. Flowchart Penelitian

Gambar 3.2 merupakan flowchart proses pembuatan tugas akhir, dimana sebelum merancang dan membuat sistem antarmuka ROV menggunakan kamera dilakukan studi pustaka terlebih dahulu yang bertujuan untuk mendapatkan referensi-referensi mengenai sistemvisi ROV Terkendali. Setelah dilakukan studi pustaka dilanjutkan dengan proses perancangan dan pembuatan sistem visi pada ROV yang dilanjutkan dengan pengujian serta analisa dan pembahasan mengenai keluaran dari sistem visi ROV yang telah dibuat dan terakhir adalah kesimpulan dan saran.

\section{HASIL ANALISIS DATA}

Dari penelitian yang telah dilakukan, dihasilkan suatu alat yang dapat digunakan untuk menampilkan gambar atau video pada computer/Pc yang di kendalikan dari jarak jauh, menggunkan joystick dan motor servo. Berbasis mikrokontroller Ardino Uno R3 seperti yang terlihat pada gambar 4.1.

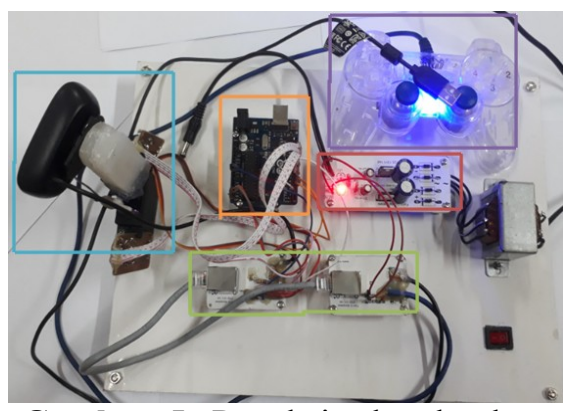

Gambar 5. Rangkaian keseluruhan
Keterangan:

1. Blok warna coklat Power suplay

2. Blok warna hijau konektor RJ45 RX-TX

3. Blok warna orange mikrokontroller Arduino Uno R3

4. Blok warna biru dua motor servo, lampu kiri-kanan dan kamera

5. Blok warna ungu Joystick dan USB kamera

\section{A. Pengujian dan analisa catu daya}

Catu daya adalah rangkaian yang dapat mengubah arus bolak-balik AC menjadi arus searah DC, dengan tegangan output yang berbeds-beda, dapat di atur sesuai keinginan kita.

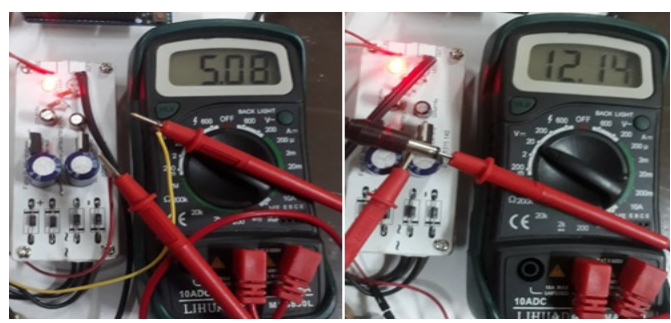

Gambar 6. Pengukuran Tegangan Power Suplay, Menggunakan multimeter digital

Tabel 1 Hasil pengukuran tegangn power suplay 12 volt dan 5 volt

\begin{tabular}{|l|c|c|c|}
\hline No. & $\begin{array}{c}\text { Tegangan } \\
\text { Input } \\
\text { (VAC) }\end{array}$ & $\begin{array}{c}\text { Tegangan } \\
\text { Output } \\
\text { Power } \\
\text { Suplay 5 Volt } \\
\text { dan 12 Volt } \\
\text { (VDC) }\end{array}$ & $\begin{array}{c}\text { Hasil } \\
\text { Pengukuran } \\
\text { Power Suplay } \\
\text { (VDC) }\end{array}$ \\
\hline $\mathbf{1 .}$ & 221 & 5 Volt & 5.08 Volt \\
\hline $\mathbf{2 .}$ & 221 & 12 Volt & $12.14 \quad$ Volt \\
\hline
\end{tabular}

\section{B. Webcam kamera Logitech C270 HD Software}

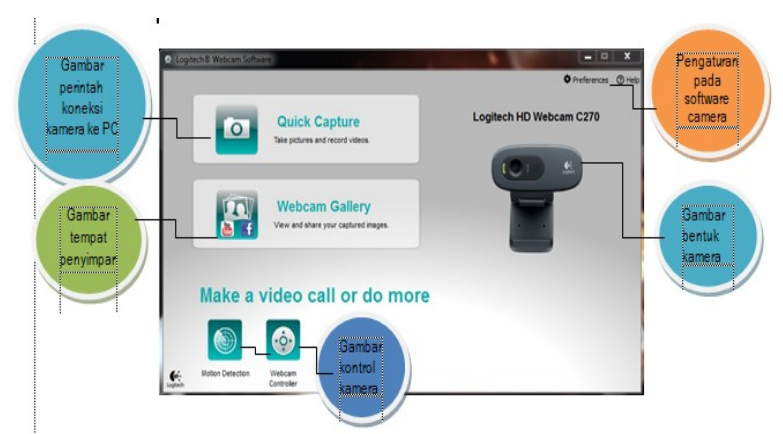

Gambar 7. Tampilan software kamera logitech C270 HD

Gambar diatas adalah software dari logitech yang suda di instal pada komputer untuk menghubungkan ke kamera logitech c270 hd, agar supaya kamera bisa kendalikan dengan PC menggunkan motor servo dan Joystick, saat pengujian sistem visi terkendali pada ROV (Remotely Operated Vehicle) tersebut. 


\section{Pengujian Tampilan Kamera pada computer}

Pengujian ini menggunakan kamera jenis webcam dengan resolusi gambar $320 \times 240$ sampai dengan 3.0 Mpixel. Webcam ini juga menggunakan port USB sebagai komunikasi data dengan komputer. Pengujian sistem visi bertujuan untuk membuktikan bahwa kamera dapat bekerja sesuai dengan perancangan yang telah di lakukan. Dari hasil pengujian dapat di lihat pada gambar 4.4

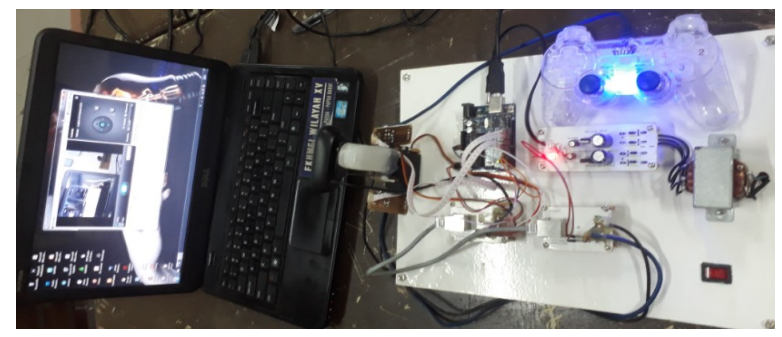

Gambar 8. Hasil pengujian kamera pada komputer

\section{a. Pengujian lebar pulsa pada motor servo vertikal}
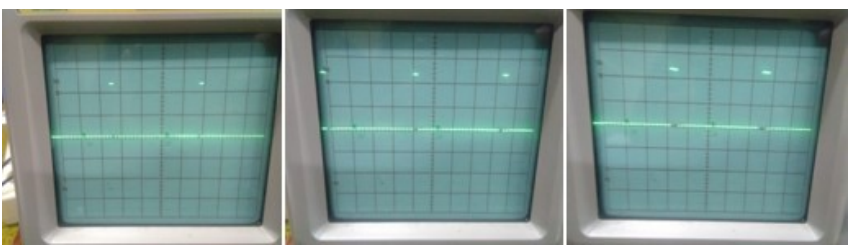

Gambar 9. Pengujian lebar pulsa vertikal

Dari pengujian yang di lihat pada layar osiloskop di atas terdapat nilai pada posisi $0^{\circ}, 45^{\circ}$ dan $90^{\circ}$ adalah $0.2 \mathrm{~ms}$, $0.4 \mathrm{~ms}$, dan $0.6 \mathrm{~ms}$ dalam satu periode. nilai ini adalah hasil perkaian dari lebar pulsa Ton $=0.1,0.2$, dan 0.3 dengan $\mathrm{T} / \mathrm{div}=2 \mathrm{~ms}$ pada osiloskop. Yang di berikan tegangan $0 \mathrm{v}-$ $5 \mathrm{v}$ dari sinyal TX pada arduino uno. Dan untuk amplitudo $=$ $4.6 \mathrm{v}$ nilai ini adalah hasil perkalian dari tinggi gelombang (amplitudo) pulsa servo dengan $\mathrm{V} / \mathrm{div}=2 \mathrm{v}$ pada osiloskop sehingga mendapatkan nilai 4.6 volt.

\section{b. Pengujian lebar pulsa pada motor servo horizontal}

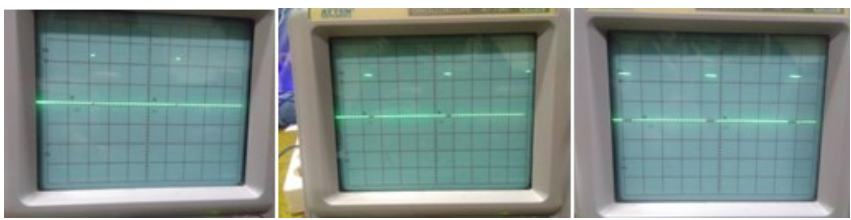

Gambar 10. Pengujian lebar pulsa horizontal

Dari pengujian yang di lihat pada layar osiloskop di atas terdapat nilai pada posisi $0^{\circ}, 45^{\circ}$, dan $90^{\circ}$ adalah $0.2 \mathrm{~ms}$, $0.6 \mathrm{~ms}$, dan $0.8 \mathrm{~ms}$ dalam satu periode. nilai ini adalah hasil perkaian dari lebar pulsa Ton $=0.1,0.3$ dan 0.4 dengan $\mathrm{T} / \mathrm{div}=2 \mathrm{~ms}$ pada osiloskop. Yang di berikan tegangan $0 \mathrm{v}-$ $5 \mathrm{v}$ dari sinyal TX pada arduino uno. Dan untuk amplitudo $=$ 4.6v nilai ini adalah hasil perkalian dari tinggi gelombang (amplitudo) pulsa servo dengan $\mathrm{V} / \mathrm{div}=2 \mathrm{v}$ pada osiloskop sehingga mendapatkan nilai 4.6 volt.

\section{Hasil Pengambilan Gambar pada Kamera}

Dari hasil pengujian kamera dengan resolusi 720p pada jarak sekitar 3 meter di depan kamera. Kamera juga bisa digunakan untuk pengambilan gambar dalam bentuk picture maupun video dan hasilnya akan tersimpan pada folder kamera dangan waktu yang di inginkan sesuai kapasitas memori pada komputer. Dan hasil tampilan gambar dan video, terlihat pada gambar 4.11 dan 4.12

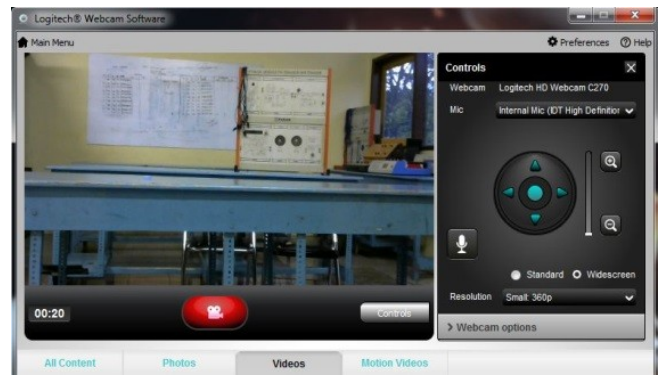

Gambar 11. Hasil tampilan dalam bentuk foto

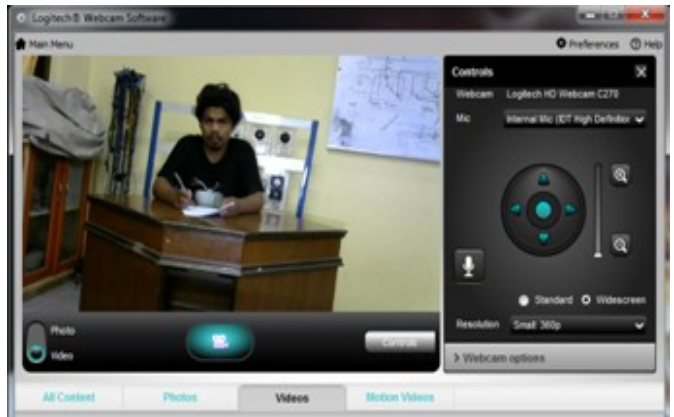

Gambar 12. Hasil tampilan video dalam bentuk foto

\section{KESIMPULAN}

Dari hasil pengujian sistem visi ROV terkendali pada tugas akhir yang telah dirancang, maka dapat di ambil beberapa kesimpulan sebagai berikut.

1. Sistem visi ROV terkendali dirancang menggunakan arduino uno R3, kamera webcam logitech, lighting dan motor servo. Kamera dan lighting pada sistem visi ROV dapat dikendalikan dengan micro motor servo $9 g \quad S G 90$ untuk melihat sisi kiri, kanan, atas dan bawah menggunakan joystick.

2. Sistem visi ROV dapat dilihat dengan buat koneksi kamera terlebih dahulu pada software webcam logitech untuk menampilkan hasil gambar atau video pada layar laptop. Proses pengiriman data dari kamera, arduino ke laptop menggunakan kabel LAN. Data yang di kirim berupa gambar, video dan gerak servo pada kamera. Untuk lebar pulsa pada servo bisa di ukur dengan menggunakan osiloskop dengan kendali menggunakan joystick 


\section{Rancang Bangun Sistem Visi Terkendali}

\section{Saran}

Adapun untuk melanjutkan penelitian ini diharapkan kedepannya. Sebagai berikut:

1. Membuat lighting secara otomatis tampa kontrol menggunakan joystick.

2. Membuat kontrol pengambilan picture dan video menggunakan tombol joystick. Sehingga tampa menekan tombol pada software kamera webcam logitech.

\section{DAFTAR PUSTAKA}

[1] M. A. Model, R. Design, O. F. Autonomous, and R. Operated, "UNDERWATER VEHICLES (AUV) AND REMOTELY OPERATED," vol. 55, no. Ii, 2012.

[2] M. S. M. Aras, S. S. Abdullah, M. Z. A. Rashid, A. A. Rahman, and M. A. A. Aziz, "Development and modeling of unmanned underwater remotely operated vehicle using system identification for depth control," J. Theor. Appl. Inf. Technol., vol. 56, no. 1, pp. 136$145,2013$.

[3] T. H. Koh, M. W. S. Lau, E. Low, G. Seet, S. Swei, and P. L. Cheng, "Preliminary Studies of the Modelling and Control of a Twin-Barrel Underactuated Underwater Robotic Vehicle," Proc. 7th Int. Conf. Control. Autom. Robot. Vision, ICARCV 2002, pp. 10421047, 2002.

[4] R. Pramana and H. Irawan, "Sistem Kamera Pengamatan Bawah Laut," J. Sustain. J. Has. Penelit. dan Ind. Terap., vol. 6, no. 1, pp. 36-43, May 2017. 